\title{
2

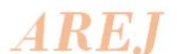 \\ Output-Input Hybrid Passive Filter Design for Electric Vehicle Charging Station
}

\author{
Shaker M. Khudher * \\ shakeralhyane@uomosul.edu.iq
}

Mohammad Lutfi Othman**

lutfi@upm.edu.my

\author{
Ishak bin Aris ** \\ ishak_ar@upm.edu.my
}

Nashiren F. Mailah**

nashiren@upm.edu.my

\footnotetext{
* Electrical Engineering Department, Collage of Engineering, University of Mosul

** Electrical and Electronic Engineering, Faculty of Engineering, University Putra Malaysia, Malaysia
}

Received: 19/2/2021

Accepted: 27/5/2021

\begin{abstract}
The impact of electric car charging stations on power grid harmonics is growing as their existence continues to expand and creates harmonic distortion in the power system. At the same time, the quality of charging current and voltage through the process of charge becomes inferior. Therefore, reduction of output ripple factor $(R F)$ and mitigation of input current harmonics is vital in this situation. This paper presents the design of the output filter and three kinds of shunt passive input filters to decrease the present harmonics generated in the industrial power scheme by the charging stations. The simulation software MATLAB/Simulink was used. Results were acquired before and after installation of filters and after installation of filters, it was found that the percentage RF of output current, voltage, and the percentage THD of the input current is reduced to match the set standards.
\end{abstract}

Keywords:

Electric Vehicle Charger; Charging Station; Passive Filters; Total Harmonic Distortion; Current Distortion

This is an open access article under the CC BY 4.0 license (http://creativecommons.org/licenses/by/4.0/).

https://rengj.mosuljournals.com

\section{INTRODUCTION}

Countries have started to create electric vehicles due to rising environmental pollution and increasing resource shortages, which require the development of comparable instruments, such as EV charging stations [1][2]. The growing presentation of non-linear equipment in the form of charging stations will result in significant harmonious grid pollution [2][3][4]. This can lead to some serious effects such as enhanced network losses and voltage fluctuations, heating issues and electrical equipment efficiency losses, power supply interruptions, or even large blackouts[3][4][5][6]. These power supply infrastructure efficiency losses will also impact the life cycle of alternative electric cars, which is crucial for choosing alternative technologies with distinct routes[7][8]. The electric vehicle companies have therefore implemented requirements for electric vehicles ' voltage and current harmonic limits[9].

The harmonic pollution from a charging station for electric vehicles stems primarily from the charger's uncontrolled or regulated rectification circuit. The grid voltage will produce a pulsating Direct voltage (VDC) on the charger after rectification by a three-phase rectifier which resulted in the generation of DC current. Current harmonic distortion occurs on the side of the charging station's Alternating Current (AC) due to the interconnection between the power grid and rectifier. Typically, for high-rated chargers with regular and rapid charging kinds, they use a threephase rectification circuit[1][2][3]. During the 
process of charging, the stations are required to charge the battery in $\mathrm{CC}$ and $\mathrm{CV}$ modes with ripple factor percentage RF for the output of less than $3 \%$ [4]. Diverse types of filters are available (an example is a passive filter) concerning the harmonic requirements mitigation to reduce the percentage THD to $<5$. The primary benefits of passive filters are their low cost, uncomplicated design, and high reliability.[5]

Several studies have been carried out to reduce harmonics by using different kinds of passive filters[10][11][12][13]. While others studies focus on new methods for filter parameters calculation and combine passive filter with other techniques like active filters, fuzzy logics , etc.[14][15][16][17][18]

This paper analyses the current charging quality as well as current harmonics at the input of an electric vehicle charger with an uncontrolled three-phase rectification circuit. Furthermore, to improve the effectiveness and design of LC output filter with single-tuned STPF, double-tuned DTPF, and second-order high passes passive HTPF input filters. The investigation is directed toward reducing the output RF percentage and the harmonic current distortion THD percentage in the industrial power system.

\section{Ripple Current Mitigation}

In most applications, the effect of ripple current should not exceed a specified value but must be mitigated if exceeded and the ripple effect from the DC output is reduced. Several methods can be used including raising the pulse number of rectifiers and the higher the number of the pulse, the lower the ripple magnitude[6]. Also, an output filter is used. If a capacitor is applied across the load and an inductor is used in series with the load, it would smoothen and lower the ripple effect[7].

The capacitor-inductor filter is used widely in high-power applications and it is connected as illustrated in Figure 1. Since there is no mathematical formula available to calculate the values of the capacitor and an inductor in capacitor-inductor filter[8][19], L and C are chosen by taking FFT for the output voltage or current then, $\mathrm{XL}=\mathrm{XC}$ at the highest harmonic frequency. The Fourier series analysis for the output voltage was used to drive Equation 1:

$$
\% R F=\frac{1}{6 \sqrt{2} L C \omega^{2}}
$$

Then to calculate $\mathrm{L}$ and $\mathrm{C}$.

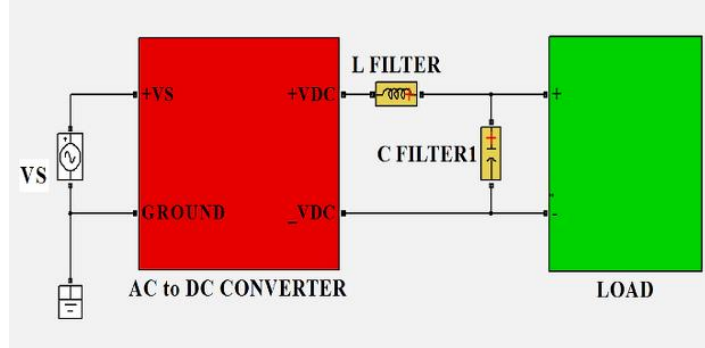

Fig. 1 LC filter connection.

\section{Harmonics Reduction}

Passive filtering is the easiest standard option to mitigate harmonic distortion[20][19]. The passive filters use passive components such as resistance, inductance, and capacitance to regulate the harmonics. Common kinds of configurations for passive filters and topologies for shunt tuning are shown in Figures 2 and 3.

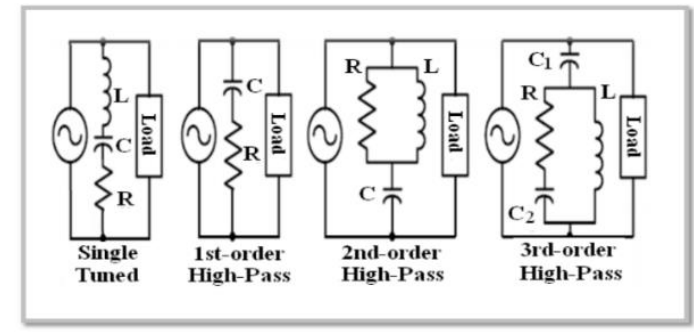

Fig.2 Type of Passive Filter

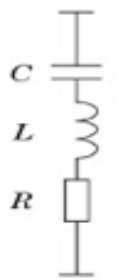

(a)

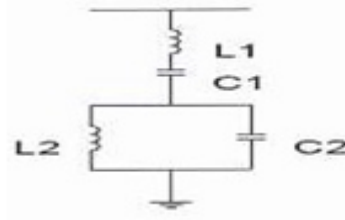

(b)
Fig.3 Passive tuned filters: (a) single-tuned (b) double-tuned

The shunt link with the power scheme of passive filters offers the least impedance path to the tuning frequency harmonic current. The filter series is intended to perform a complete load current compared to the shunt filter series while the passive shunt filter has a portion of the filter current in the series. They, therefore, need excessive protective devices. The series filter is comparatively more costly and therefore passive shunt filter is widely used as a harmonic filter. It also offers reactive power at the frequency of operation of the device 


\section{Single Tuned Filter Design}

The passive single-tuned filter is the most common filter used also, it is easy and cheaper than other ways to mitigate harmonic issues[5][21]. The most prevalent and cheap form of passive filter is the STF (Single Series Filter), it can be linked to the central distribution system in shunt and tune to a specific harmonic frequency with low impedance. Therefore, harmonic currents are diverted through the filter from the least impedance path. It is essential to select the suitable capacitor value for the design of the single tuned filter which allows excellent power factor at system frequency. The circuit diagram of the STF is shown in Figure. 3(a)

The correct choice of capacitor size is essential from a power factor point of perspective in the design of the filter. Equation 2 displays the relationship between capacitor reaction and reactive power:

$$
Q=\frac{\left(V_{r m s}\right)^{2}}{X C}
$$

where Vrms is the line voltage, $\mathrm{Q}$ is the reactive power in $\mathrm{kVAR}$, and $\mathrm{XC}$ is the capacitive reactance of capacitor in ohms. From Equation 2, the value of capacitance (in Farad) is calculated as:

$$
C=\frac{Q}{(2 \pi f) \times\left(V_{r m s}\right)^{2}}
$$

Where $\mathrm{f}$ is the fundamental frequency.

When the capacitive reaction is equivalent to inductive reaction as at a particular frequency, the resonance condition will occur as:

$$
\mathrm{XL}=\mathrm{XC}
$$

Then L can be found from Equation 5

$$
\begin{aligned}
& L= \frac{1}{\left(2 \pi f_{n}\right)^{2} \times C} \\
& f_{n}=\text { (FundamentalFreq. }) \\
& \times n
\end{aligned}
$$

Where $\mathrm{n}=2,3,4,5,6 \ldots$ etc

While the resistance $(\mathrm{R})$ can be calculated using Equation 6.

$$
Q c=\sqrt{L / C} /_{R}
$$

Notice that for this type of filter the quality factor is given as[22]:

$$
\mathbf{5 0}<Q_{c}<\mathbf{1 5 0}
$$

\section{Double Tuned Filter Design}

The conventional double-tuned filter is composed of the series resonance circuit and parallel resonance circuit. The structure of this type of filter is shown in Figure.2(b)[23].

The series resonance circuit $\left(\mathrm{L}_{1}, \mathrm{C}_{1}\right)$ and parallel resonance circuit $\left(\mathrm{L}_{2}, \mathrm{C}_{2}\right)$ have resonance frequencies $\omega_{\mathrm{s}}$ and $\omega_{\mathrm{p}}$ respectively. They can be formulated as:

$$
\left[\begin{array}{l}
\omega_{s} \\
\omega_{p}
\end{array}\right]=\left[\begin{array}{c}
\frac{1}{\sqrt{L_{1} C_{1}}} \\
\frac{1}{\sqrt{L_{2} C_{2}}}
\end{array}\right]
$$

The impedance of this filter is:

$$
\begin{aligned}
& Z=j \omega L_{1}+\frac{1}{j \omega C_{1}}+\left(j \omega C_{2}+\frac{1}{j \omega L_{2}}\right)^{-1} \\
& Z=\frac{\left(1-\frac{\omega^{2}}{\omega_{s}^{2}}\right)\left(1-\frac{\omega^{2}}{\omega_{p}^{2}}\right)-\omega^{2} L_{2} C_{1}}{j \omega C_{1}\left(1-\frac{\omega^{2}}{\omega_{p}^{2}}\right)}
\end{aligned}
$$

To calculate the parameters for this filter, two single-tuned filters connected in parallel are used with neglecting branch resistance as shown in Figure 4.

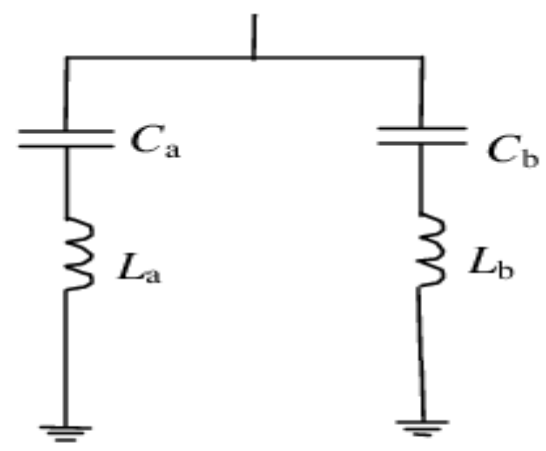

Fig. 4 Parallel two single tuned filter 
The steps that describe the conversion method to calculate the filter parameter as described[23]. Starting from the resonance frequencies which can be obtained from Equation 10 for both branches shown in Figure 4.

$$
\left[\begin{array}{c}
\omega_{a} \\
\omega_{b}
\end{array}\right]=\left[\begin{array}{c}
\frac{1}{\sqrt{L_{a} C_{a}}} \\
\frac{1}{\sqrt{L_{b} C_{b}}}
\end{array}\right]
$$

While the impedance of the two-parallel single tuned can be expressed as:

$$
\begin{aligned}
& Z_{a b}=\left(\left(j \omega L a+\frac{1}{j \omega C_{a}}\right)^{-1}\right. \\
& \left.+\left(j \omega L b+\frac{1}{j \omega C_{b}}\right)^{-1}\right)(-1) \\
& Z_{a b}=\frac{\left(1-\frac{\omega^{2}}{\omega_{a}^{2}}\right)\left(1-\frac{\omega^{2}}{\omega_{b}^{2}}\right)}{j \omega C_{a}\left(1-\frac{\omega^{2}}{\omega_{b}^{2}}\right)+j \omega C_{b}\left(1-\frac{\omega^{2}}{\omega_{a}^{2}}\right)}
\end{aligned}
$$

Both configuration in Figure 2 (b) and 4 are equivalent, that means they have equal impedance $\mathrm{Z}=\mathrm{Z}_{\mathrm{ab}}$. From Equations 9 and 12 it can be seen that both have the same constant term of 1 , so they have equal molecular and denominator. After analysing the coefficients of order $\omega^{4}$ the following equation can be obtained:

$$
\omega_{a} \omega_{b}=\omega_{s} \omega_{p}
$$

And for coefficients of order $\omega$ :

$$
C_{1}=C_{a}+C_{b}
$$

While for coefficients of order $\omega^{3}$ it can be found as:

$$
C_{b} \frac{1}{\omega_{a}^{2}}+C_{a} \frac{1}{\omega_{b}^{2}}=C_{1} \frac{1}{\omega_{p}^{2}}
$$

The inductance $L_{1}$ can be found from Equations 16 :

$$
L_{1}=\frac{1}{C_{a} \omega_{a}^{2}+C_{b} \omega_{b}^{2}}
$$

Appling $\mathrm{C}_{1}, \mathrm{~L}_{1}$ in Equation 5 and using Equation 13 to obtain $\omega_{s}$ and $\omega_{p}$ also, since $\omega_{a}$ represent the zero of double-tuned filter impedance then $\mathrm{Z}$ $\left(\omega_{a}\right)=0$ as shown in Equation 17:

$$
\left(1-\frac{\omega_{a}^{2}}{\omega_{s}^{2}}\right)\left(1-\frac{\omega_{a}^{2}}{\omega_{p}^{2}}\right)-\omega_{a}^{2} L_{2} C_{1}=0
$$

From Equation, $18 \mathrm{~L}_{2}$ can be obtained:

$$
L_{2}=\frac{\left(1-\frac{\omega_{a}^{2}}{\omega_{s}^{2}}\right)\left(1-\frac{\omega_{a}^{2}}{\omega_{p}^{2}}\right)}{\omega_{a}^{2} C_{1}}
$$

Then from Equations 13, 18, the value of $\mathrm{C}_{2}$ can be found using the following equation:

$$
C_{2}=\frac{1}{L_{2} \omega_{p}^{2}}
$$

\section{Second-order high pass passive filter design}

This type of filter consists of a capacitor that is connected in series with a parallel branch that includes inductance and resistance as shown in Figure 2. The filter elements are sized such that the filter works below the tuning frequency like the single-tuned filter and like the first-order high-pass filter at high frequencies. The behaviour of this filter acts like small inductive reactance in low frequencies bypassing the resistive branch and as a large inductive reactance in high frequencies diverting the current to the resistor branch. At the tuning frequency, a notch can be observed. This performance is achieving when the capacitor is tuned to the desired frequency with the inductor. The impedance is given by Equation 20[19][21][24]:

$$
Z=\frac{R L C S^{2}+L S+R}{S(C L S+C R)}
$$

To calculate the parameters for this type the following equations are used[25] .

$$
\begin{aligned}
& f_{n}=\frac{1}{2 \pi \times C \times R} \\
& \therefore R=\frac{1}{2 \pi f_{n} \times C} \\
& m^{2}=\frac{L}{R^{2} C} \\
& \therefore L=m^{2} R^{2} C
\end{aligned}
$$


Where $\mathrm{m}$ is a factor that changes the inductance value of this type of filter. When the inductance value increases, the filter action is approached from the low frequencies, and when the inductance value is reduced, the filter action is approaching the high frequencies; $\mathrm{m}$ is a factor that changes the filter's working point only. The practical value of this factor is $0.5<\mathrm{m}<2$ [24]

\section{Filter Configuration Selection}

At lower harmonic frequencies, most waveforms have a significant proportion of harmonic distortion compared to elevated harmonic frequencies. That is why singletuned filters are intended in the first stage to restrain the frequencies that deal with lower harmonic while DTF is used in the second stage.

Four STF are used to restrain $5^{\text {th }}, 7^{\text {th }}, 11^{\text {th, }}$ and $13^{\text {th }}$ harmonics of six pulse ac to dc converter, while a one-second high-pass filter is used to eliminate high-order frequencies. Then the four single-tuned filters are converted to two double-tuned filters $\left(5^{\text {th }} \& 7^{\text {th }}\right)$ and $\left(11^{\text {th }} \& 13^{\text {th }}\right)$.

\section{Simulation and Results}

In this study, three-phase full-wave uncontrolled six diodes AC to DC converters that are charging an electric car represented by a battery in the form of RLE has been simulated before and after using suggest passive filters in the MATLAB/Simulink environment. Table 1 present the circuit parameters used in the simulation and the complete simulation diagram as explained in Figure 5.

Table1: Simulation Parameters.

\begin{tabular}{|l|l|}
\hline Parameter & Value \\
\hline \hline Supply voltage (L-L) & $11000 \mathrm{~V}$ \\
\hline Supply frequency F & $50 \mathrm{~Hz}$ \\
\hline $\begin{array}{l}\text { Source impedance } \\
\text { (Rs, Ls) }\end{array}$ & $1 \mathrm{~m} \Omega, 0.1 \mathrm{mH}$ \\
\hline $\begin{array}{l}\text { Load (electric car } \\
\text { battery RLE) }\end{array}$ & $\begin{array}{l}300 \mathrm{~V}, 50 \mathrm{~A}, \quad 2 \\
\Omega, 10 \mathrm{mH}\end{array}$ \\
\hline $\begin{array}{l}\text { Charger Output } \\
\text { Voltage and Current }\end{array}$ & $450 \mathrm{~V}, 75 \mathrm{~A}$ \\
\hline $\begin{array}{l}\text { Three Phase } \\
\text { Transformer Yg/Yg }\end{array}$ & $\begin{array}{l}100 \mathrm{KVA}, 50 \mathrm{H} \\
11000 / 483 \mathrm{~V}\end{array}$ \\
\hline
\end{tabular}

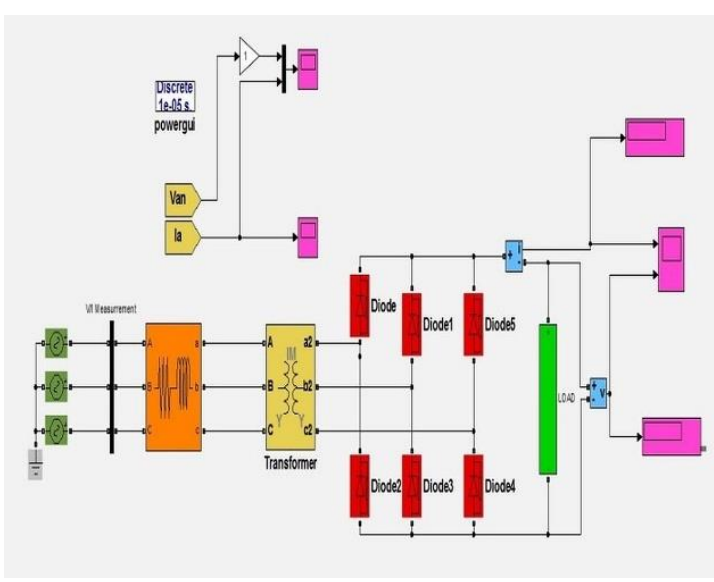

Fig .5 Uncontrolled Six-diode Converter

The system studied in three cases as elucidating:

Case 1: Without Filters

This case represents the simulated circuit without any filters. The output voltage and current, in this case, are as shown in Figure 6, while the input voltage and current are explained in Figure 7.
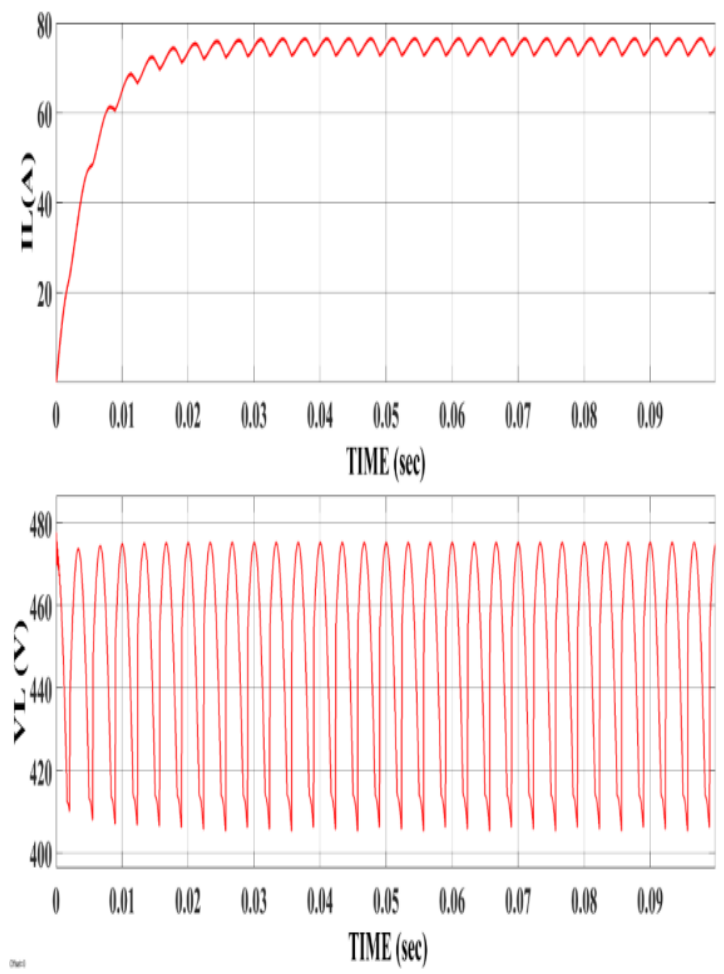

Fig.6 Output voltage (VL) and output current (IL) for six diodes rectifier 

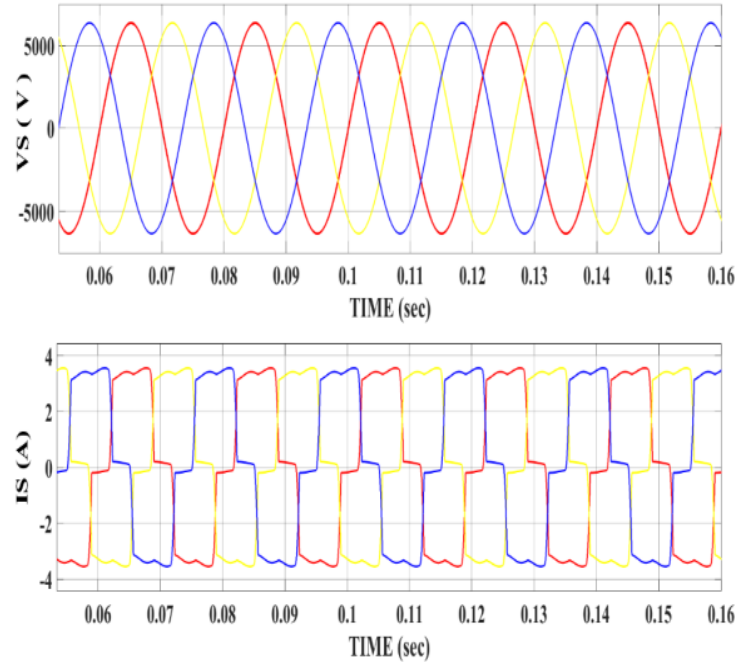

Fig.7 Three-phase input voltage and current for six diode rectifiers

From Figure 6, it can be noticed that the output ripple for both voltage and current is too high and not acceptable according to standards. While Figure 7, shows that the input current for this case is wholly distorted with THD $=25.56 \%$ as indicated by the FFT analysis in Figure 8 .

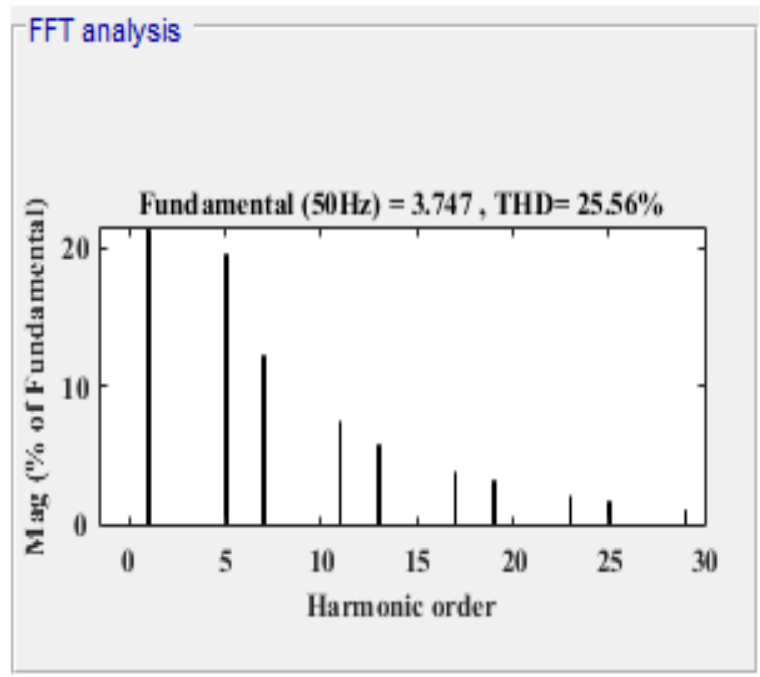

Fig.8 FFT analysis for the input current in six diodes rectifier

Case 2: With LC output filter

As explained earlier an LC filter is used to reduce the output ripple factor RF while the value of $\mathrm{L}$ and $\mathrm{C}$ can be calculated by taking the FFT analysis for the output voltage or current. It can be noticed that the highest harmonics frequency is the $6^{\text {th }}$ which equal to $300 \mathrm{~Hz}$ as shown in Figure 9.

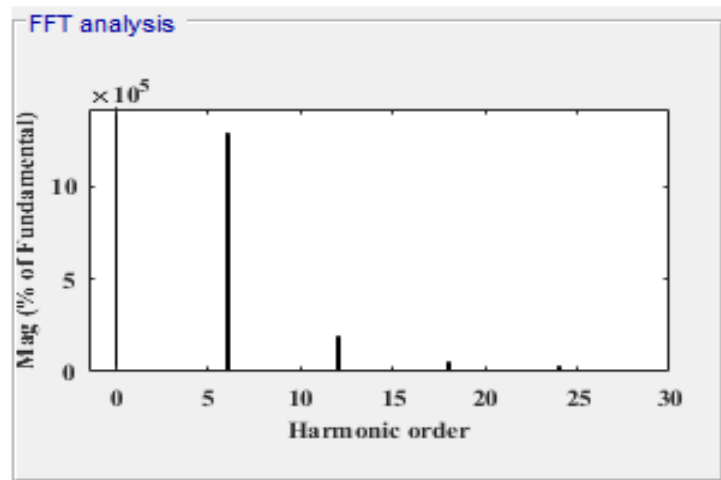

Fig.9 FFT analysis for output current

By using Equation 5 at $\mathrm{f}=300 \mathrm{~Hz}$ with chosen $\mathrm{C}=470 \mathrm{mF}$, the value of $\mathrm{L}=59.88 \mu \mathrm{H}$. Depending on this value, the circuit diagram transforms to Figure 10.

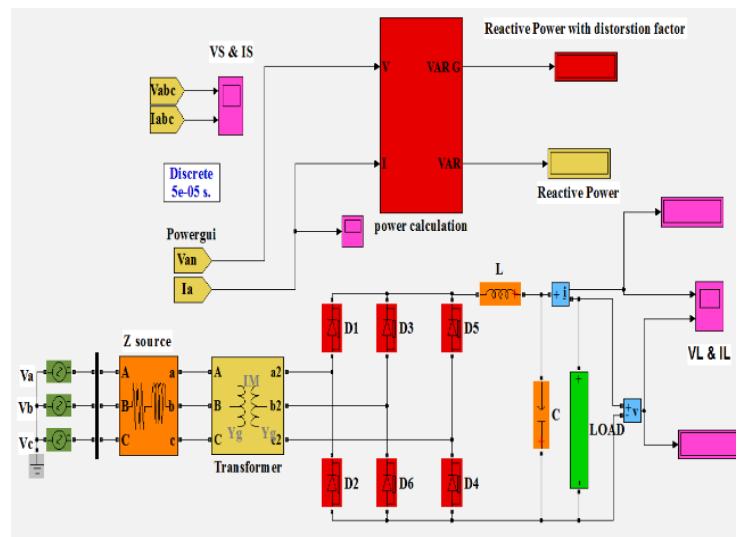

Fig.10 Six diodes with an LC output filter

The ripple factor of the output voltage and current after the connection of the LC filter becomes less than $3 \%$ as explained in Figure 11
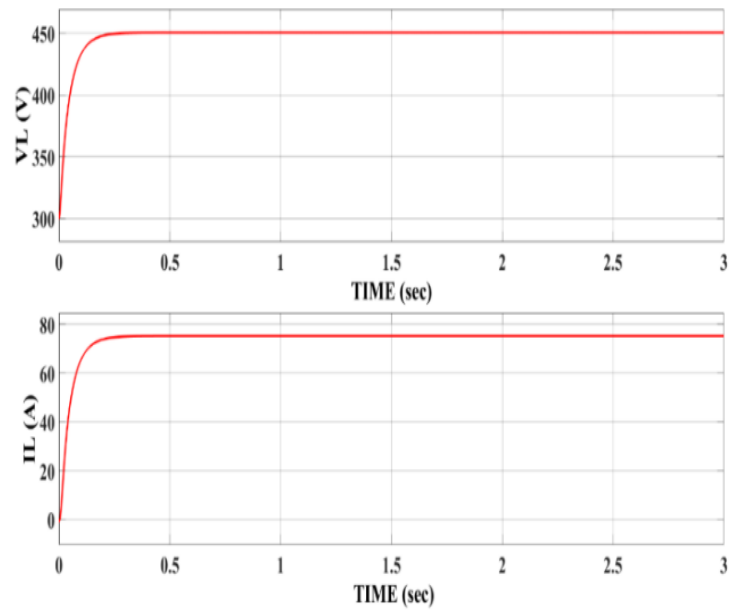

Fig.11 Output voltage and current with output LC filter 
Due to the connection of the LC filter at the output side, the input current becomes more distorted, and the \% THD increased from $25.56 \%$ to $46.19 \%$ as shown in Figure 12 and Figure 13.
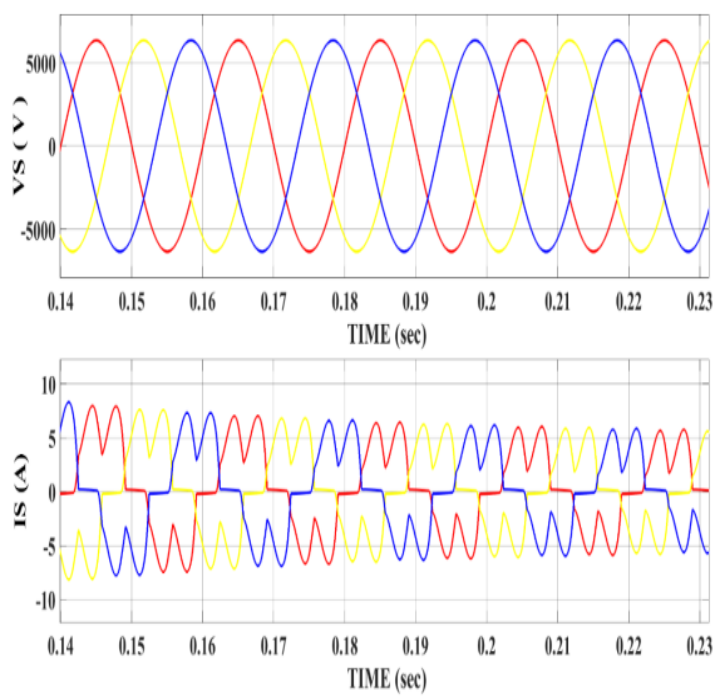

Fig.12 Input voltage and current with output LC filter

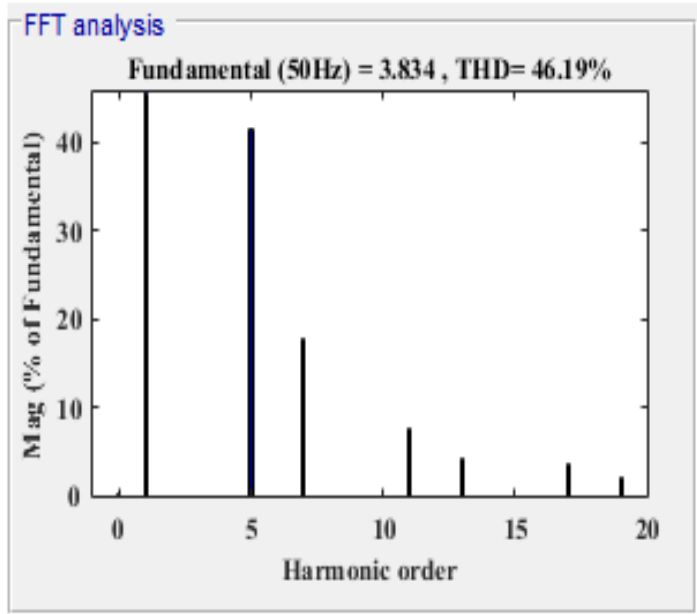

Fig.13 FFT analysis of the input current with output LC filter

Case 3: With both output and input filters

In this case, two types of the passive filter were designed depending on the following values:

Total VAR in the system Q $=19.272$ KVAR, Quality factor $=70, \mathrm{~m}=2$.

- Single tuned passive filter (STPF) designed for the harmonics 5, 7,11, and 13 while high pass passive filter designed for harmonics 17 to $\infty$ and the filter parameters is as shown in Table 2.
Table2: STPF with HTPF parameters for six diodes with a car.

\begin{tabular}{|c|c|c|c|c|}
\hline $\begin{array}{l}\text { Harmonic } \\
\text { order }\end{array}$ & $\begin{array}{l}\text { Type of } \\
\text { filter }\end{array}$ & $\bar{C} \mathrm{C}(\mu \mathrm{F})$ & $\begin{array}{l}\mathrm{L} \\
(\mathrm{mH})\end{array}$ & R R (ohm) \\
\hline 5 & \multirow{4}{*}{$\begin{array}{l}\text { SINGLE } \\
\text { TUNED } \\
\text { FILTER } \\
\text { (STPF) }\end{array}$} & 3.0416 & 133.2 & 2.7908 \\
\hline 7 & & 3.0416 & 68.0 & 1.9934 \\
\hline 11 & & 3.0416 & 27.5 & 1.2685 \\
\hline 13 & & 3.0416 & 19.7 & 1.0734 \\
\hline $17-\infty$ & $\begin{array}{l}\text { HIGH } \\
\text { TUNED } \\
\text { FILTER }\end{array}$ & 3.0416 & 5.8 & 61.5607 \\
\hline
\end{tabular}

By simulating the parameters mentioned in Table 2 , the system filter set can obtain as described in Figure 14 and the circuit diagram after the filter connection is illustrated in Figure 15

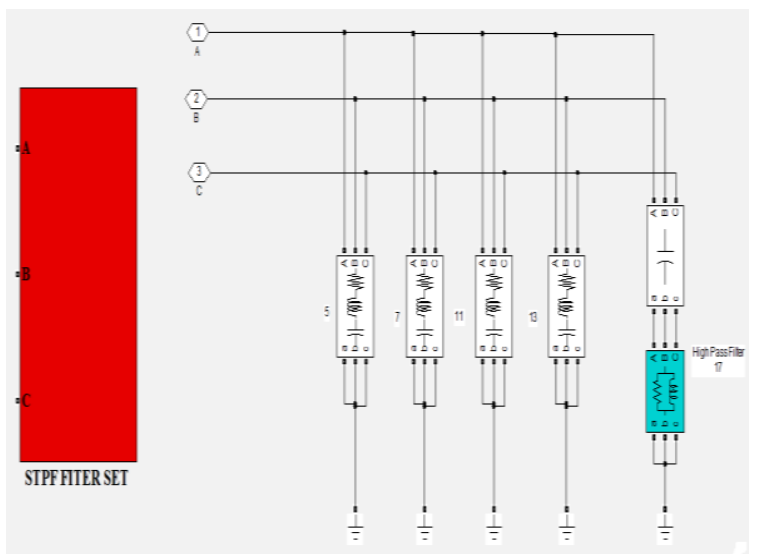

Fig.14 STPF system simulation

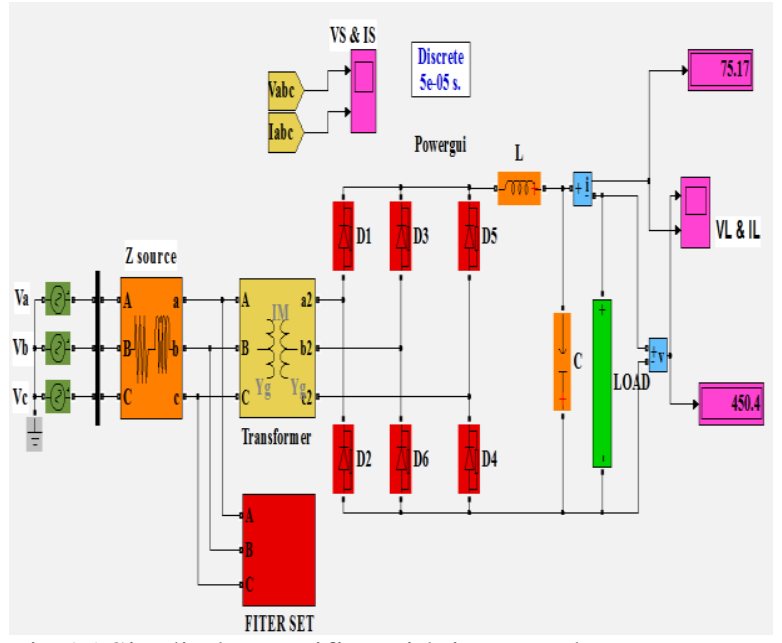

Fig.15 Six diodes rectifier with input and output filters 
- A double-tuned passive filter (DTPF) is designed by converting STPF to DTPF. Every two arms of STPF will be turned to one arm DTPS in this case for 5, 7, and 11,13 , the two DTPF arms can be used while for 17 to $\infty$ still using high pass filter. The parameters for DTPF are described in Table 3.

Table3: DTPF Parameters.

\begin{tabular}{|c|c|c|c|c|c|}
\hline Order & $\begin{array}{l}\text { Filter } \\
\text { Type }\end{array}$ & $\begin{array}{l}\mathrm{C} 1 \\
(\mu \mathrm{F})\end{array}$ & $\begin{array}{l}\mathrm{L} 1 \\
(\mathrm{mH})\end{array}$ & $\begin{array}{l}\text { C2 } \\
(\mu F)\end{array}$ & $\begin{array}{l}\mathrm{L} 2 \\
(\mathrm{mH})\end{array}$ \\
\hline $5 \& 7$ & \multirow{2}{*}{ DTF } & 6.08 & 45 & 57.83 & 5.3 \\
\hline $11 \& 13$ & & 6.08 & 11.5 & 222 & 0.323 \\
\hline
\end{tabular}

Referring to the circuit mention in Figure 15 and using a filter system explained in Figure 14, the output voltage and current are constant as described in Figure 11 while the input voltage and current are shown in Figure 16. Applying FFT analysis for the input current results obtained shows that the THD decreased from $46.19 \%$ as apparent in Figure 13 to $5.81 \%$ as shown in Figure 17 which is still higher than the value of the standards of $5 \%$.
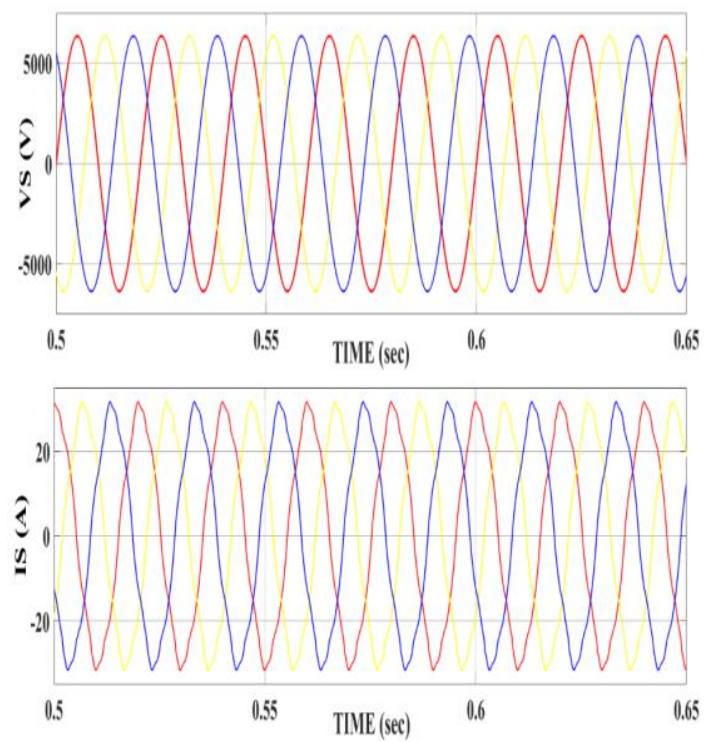

Fig.16 Input voltage and current for six diodes rectifier with STPF +HTPF

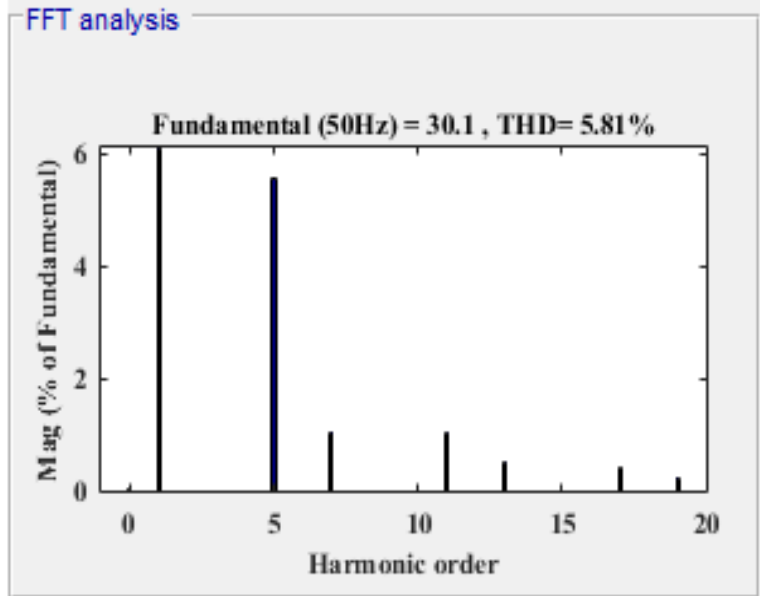

Fig.17 FFT analysis of the input current with an input filter

To solve this issue and reduce the THD below 5\% the STPF is converted to double-tuned passive filter DTPF.

The output voltage and current are the same in Figure 11 while the input voltage and current are as shown in Figure 18
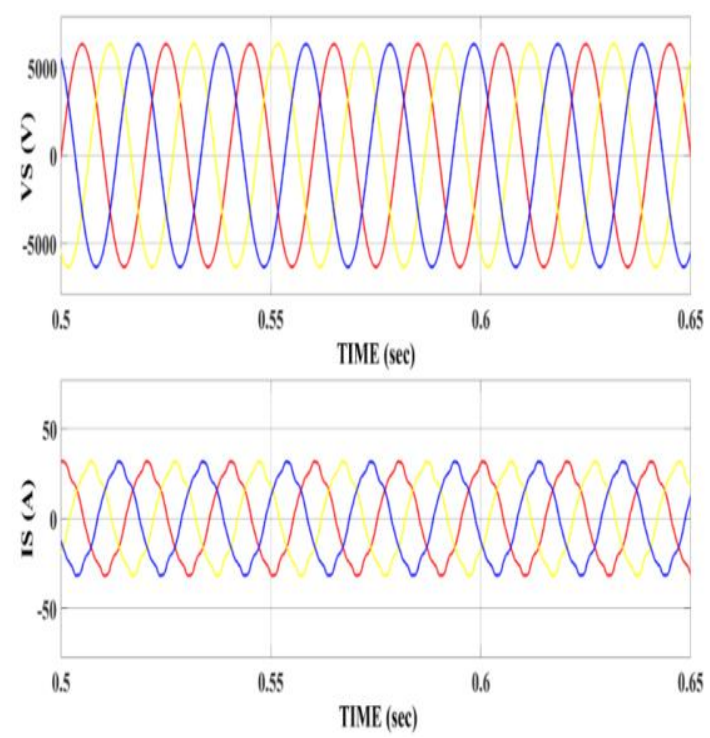

Fig.18 Input voltage and current with DTPF filter

After taking the FFT analysis for the input current, the total harmonics distortion THD is reduced from $46.19 \%$ to $3.73 \%$ as shown in Figure 19. This confirmed the effectiveness of DTPF as compare with the STPF set to match the standards values of THD which is below 5\% and the summarized variation of the \%THD for this circuit is as shown in Figure 20. 


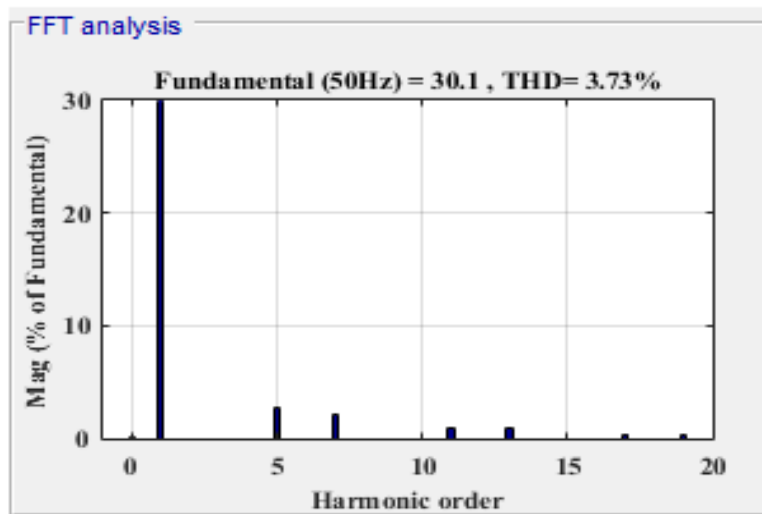

Fig.19 input current FFT analysis with DTPF

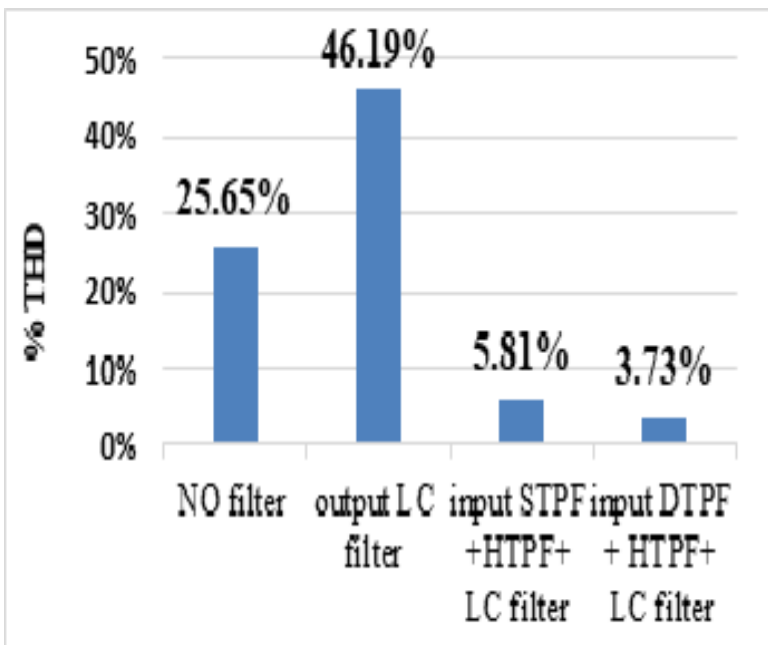

Fig.20 Variation of the \% THD for six diodes rectifier with car

\section{CONCLUSION}

A PC-based design technique for prevalent kinds of passive filters output and input namely LC filter for the output and single, double-tuned filters and high pass filter for input has been presented in this study. The proposed LC filters reduced the output ripple factor to match the standards but increase the THD of the source current from $25.56 \%$ to $46.19 \%$. While the combination of STPF with HTPF reduced the \%THD from $46.19 \%$ to $5.81 \%$ in the simulation which was still out of the standards $(<5 \%)$. On the other hand, the conversion of STPF to DTPF combined with DTPF decreases the THD percentage from $46.19 \%$ to $3.73 \%$ which met the IEEE 519 recommended harmonic standards. The scope of using such filters is the size of filters as compare with other types but it is very cheap.

\section{ACKNOWLEDGEMENTS}

University Putra Malaysia supported this work under grant ref: (GP-IPB)/ (2013-9412103). The author would like to thank The Ministry of Higher Education and Scientific Researches/Iraq, and Mosul University, College of Engineering, electric department for providing the research grant.

\section{REFERENCES}

[1] A. Kuperman, U. Levy, J. Goren, A. Zafransky, and A. Savernin, "Battery charger for electric vehicle traction battery switch station," IEEE Trans. Ind. Electron., vol. 60, no. 12, pp. 5391-5399, 2013, doi: 10.1109/TIE.2012.2233695.

[2] T. B. Soeiro, T. Friedli, and J. W. Kolar, "Design and implementation of a three-phase buck-type third harmonic current injection PFC rectifier SR," IEEE Trans. Power Electron., vol. 28, no. 4, pp. 1608-1621, 2013, doi: 10.1109/TPEL.2012.2209680.

[3] K. M. Yoo, K. D. Kim, and J. Y. Lee, "Singleand three-phase PHEV onboard battery charger using small link capacitor," IEEE Trans. Ind. Electron., vol. 60, no. 8, pp. 31363144, 2013, doi: 10.1109/TIE.2012.2202361.

[4] S. M. Khudher, I. Bin Aris, N. F. Mailah, and R. K. Sahbudin, "Analysis of AC - To - DC uncontrolled converters harmonics for electric vehicles applications," Pertanika J. Sci. Technol., vol. 25, no. S, pp. 283-290, 2017, [Online]. Available: http://www.pertanika.upm.edu.my/.

[5] Z. Memon, M. Uquaili, and M. Unar "Harmonics Mitigation of Industrial Power System Using Passive Filters," Mehran Univ. Res. J. Eng. Technol., vol. 31, no. 2, pp. 355360, 2012.

[6] B. Singh, G. Bhuvaneswari, V. Garg, and S. Gairola, "Pulse Multiplication in AC-DC Converters for Harmonic Mitigation in Vector-Controlled Induction Motor Drives," IEEE Trans. Energy Convers., vol. 21, no. 2, pp. 342-352, 2006, doi: 10.1109/TEC.2006.874217.

[7] M. Subbamma, V. Sudhan, K. Anjaneyulu, and P. Sujatha, "Design Aspects and Analysis For Higher Order Harmonic Mitigation of Power Converter Feeding A Vector Controlled Induction Motor Drives," IEEE - Int. Conf. Adv. Eng. Sci. Manag. (ICAESM), 2012, pp. 282-287, 2012.

[8] D. Legese, "Harmonic Analysis of Addis Ababa Light Rail Transit Traction Converters," Addis Ababa University, 2014.

[9] J. C. Das, "Passive filters - potentialities and limitations," IEEE Trans. Ind. Appl., vol. 40, no. 1, pp. 232-241, 2004, doi: 
10.1109/TIA.2003.821666.

[10] E. Sarwono, E. Apriaskar, and N. Azis Salim, "Investigate quality factor of single tuned passive filter to reduce harmonic of LED lamp," in Journal of Physics: Conference Series, 2020, vol. 1444, no. 1, doi: 10.1088/1742-6596/1444/1/012024.

[11] P. Ranga and M. Mittal, "Harmonic reduction in induction motor using harmonic injection method and passive filter: A comparison," 2020, doi:

10.1109/ICMICA48462.2020.9242750.

[12] Asmahan Y. Husen, Kamal H.Younis, and Ameen A. Fatah, "High Harmonic Reduction Using Passive Filters of Mountain Steel Company," Zanco J. Pure Appl. Sci., vol. 33, no. 1, pp. 178-187, 2021, doi: 10.21271/zjpas.33.1.19.

[13] G. Kolap, S. U. Bagwan, P. Chougule, B. Ghule, and N. Nangare, "Harmonic mitigation by shunt passive power filter at voltage source type non-linear load," in Proceedings of the 5th International Conference on Communication and Electronics Systems, ICCES 2020, 2020, pp. 84-89, doi: 10.1109/ICCES48766.2020.09138092.

[14] Mushfiqul Ahmed, Nahid-Al-Masood, S.M. Ishraqul Huq, Ferdous Irtiaz Khan, Hridi Juberi, and Shamiul Bashar, "A Comprehensive Modeling of Double Tuned Filter for Efficient Mitigation of Harmonic Distortion," in International Conference on Smart Grids and Energy Systems (SGES) 2020, 2020, pp. 350-355.

[15] Ahmed M. Zobaa, S. H. E. A. Aleem, and H. K. M. Youssef, "Comparative Analysis of Double-Tuned Harmonic Passive Filter Design Methodologies Using Slime Mould Optimization Algorithm Ahmed," in 2021 IEEE Texas Power and Energy Conference (TPEC), 2021, pp. 1-6.

[16] R. Klempka, "Optimal Double-Tuned Filter Efficiency Analysis," IEEE Trans. Power Deliv., vol. 36, no. 2, pp. 1079-1088, 2021, doi: $10.1109 /$ tpwrd.2020.3001831.

[17] S. B. Abood and T. M. Abdul-Wahhab, "Investigation of Harmonic Reduction Using Passive Filters in a Distribution Network in Basra City," IOP Conf. Ser. Mater. Sci. Eng., vol. 1067, no. 1, p. 012124, 2021, doi: 10.1088/1757-899x/1067/1/012124.

[18] KIRAN YADDANAPUDI and PANNALA KRISHNA MURTHY, "PERFORMANCE ANALYSIS OF FUZZY LOGIC CONTROLLED HYBRID ACTIVE DC FILTER (HADF) FOR 12-PULSE HVDC CONVERTER," Int. J. Emerg. Trends Eng. Res., vol. 9, no. 2, pp. 70-74, 2021, doi: 10.30534/ijeter/2021/10922021.

[19] G. Mishra and S. Gopalakrishna, "Design of Passive High Pass Filter for Shunt Active Power Filter Application," Int. Conf. Circuits,
Power Comput. Technol., pp. 17-21, 2013, doi: 10.1109/ICCPCT.2013.6528947.

[20] A. Nassif, W. Xu, and W. Freitas, "An Investigation on the Selection of Filter Topologies for Passive Filter Applications," IEEE Trans. Power Deliv., vol. 24, no. 3, pp. 1710-1718, 2009, doi: 10.1109/TPWRD.2009.2016824

[21] R. C. Dugan, M. F. F. Mcgranaghan, S. Santoso, and H. W. Beaty, Electrical power systems quality, Third Edit. McGraw-Hill Education, 2012.

[22] F. C. D. La Rosa, Harmonics and power systems. CRC press, 2006.

[23] H. Yi-hong and S. Heng, "A New Method of Designing Double-tuned Filter," Proc. 2nd Int. Conf. Comput. Sci. Electron. Eng., no. Iccsee, pp. 206-209, 2013, doi: 10.2991/iccsee. 2013.54

[24] K. Srivastava, S. Shakil, and A. Panchbhai, "Harmonics \& Its Mitigation Technique by Passive Shunt Filter," Int. J. Soft Comput. Eng., vol. 3, no. 2, pp. 325-331, 2013.

[25] J. Das, Power System Harmonics and Passive Filter Designs, Second edi. John Wiley \& Sons, 2015 


\section{تصميم مرشح غير فعال في الاخراج والادخال لمحطات شحن السيارات الكهربائية}

\author{
إسحاق ارايس** \\ ishak ar@upm.edu.my \\ *ناشرين فرز الله ماليح**ir \\ nashiren@upm.edu.my
}

\author{
شاكر محمود خضير \\ shakeralhyane@uomosul.edu.iq \\ ** محمد لطفي عثمان \\ lutfi@upm.edu.my
}

جامعة الموصل - كلية الهندسة ـ قسم الهندسة الكهربائية

كلية الهندسة -جامعة بوتر الماليزية المناسية

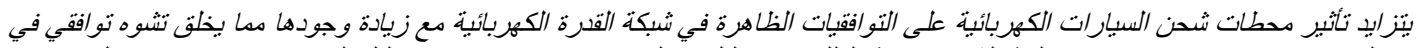

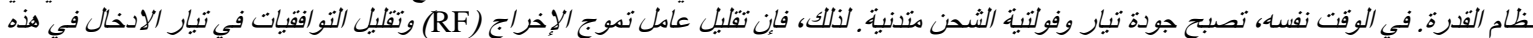

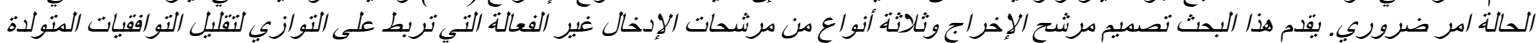

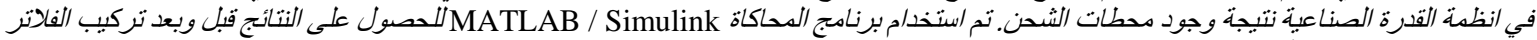

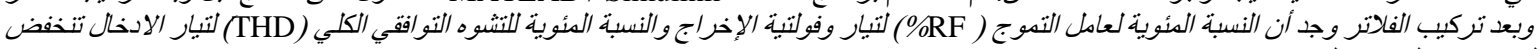

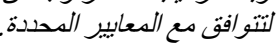

الكلمات الدالة:

شاحنة السيارة الكهربائية، محطة الشحن، المرشحات غبر الفعالة، التشوه التواققي الكلي، تشوه التيار. 